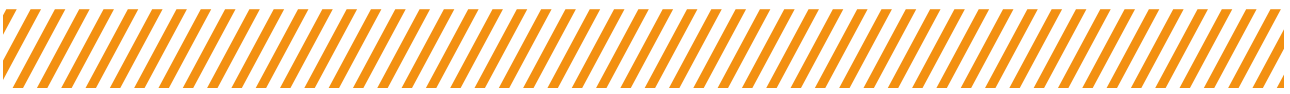

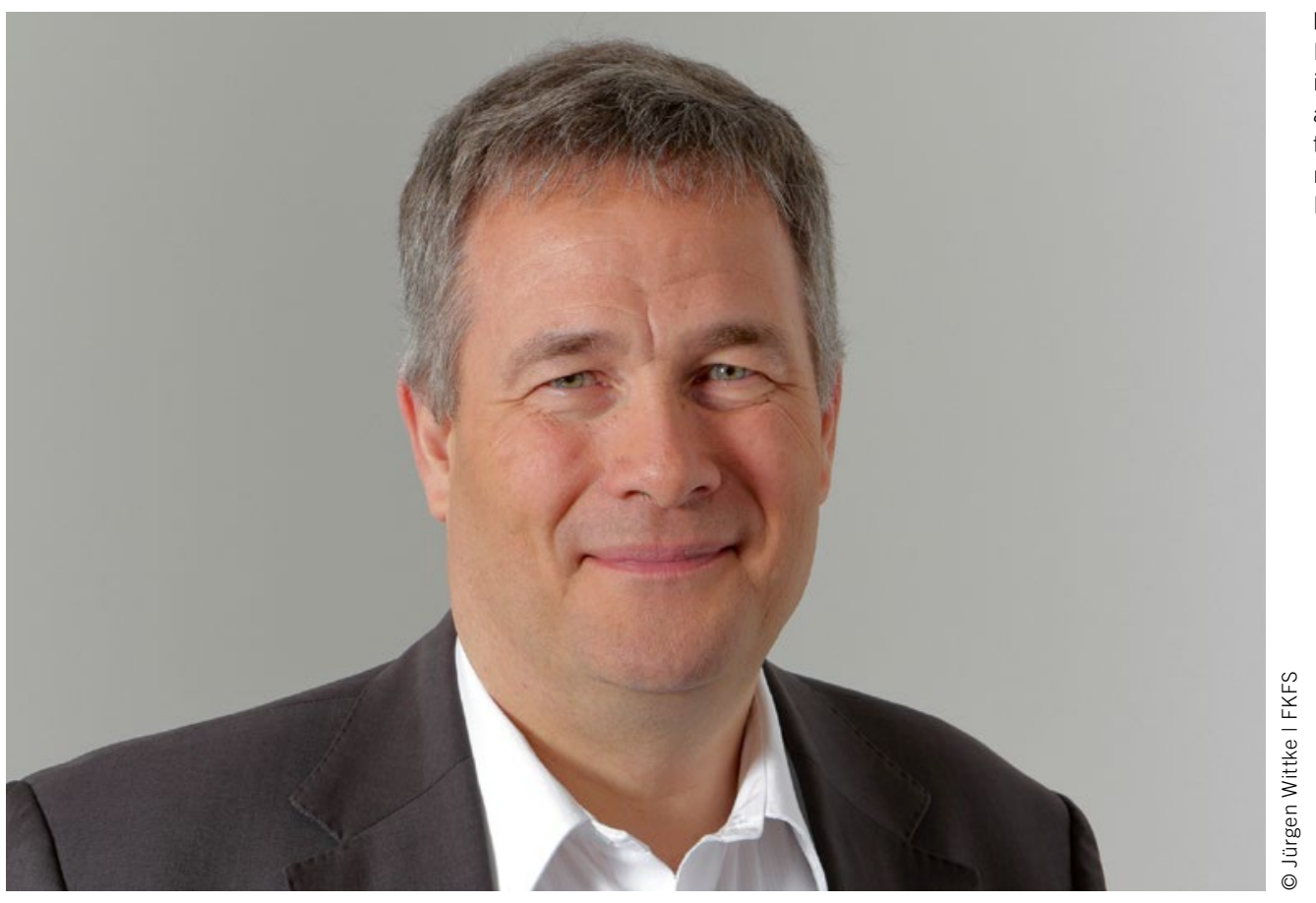

Prof. Dr. Hans-Christian Reuss Director of Automotive Mechatronics at the University of Stuttgart and Executive Board Member of the Research Institute of Automotive Engineering and Vehicle Engines Stuttgart (FKFS)

\section{Technology for People}

If I had to decide all over again what career I should pursue, I would again go into engineering. As a matter of fact, I love my profession and technology in general. Many of the engineers I know feel the same way. Moreover, we are currently experiencing a rapid increase in the number and rate at which new technologies are made available to us. This is further expanding the horizon for engineers working in various fields, particularly in areas that require interdisciplinary approaches. Let's take vehicle automation and connectivity as an example. Driver assistance systems have vastly improved in recent years - from ABS to ever higher levels of automation - leaving us with an abundance of new functions. Digitalization and artificial intelligence are a self-evident part of our development environments. Industry organizations such as SAE, BAST and VDA have taken on the task of ordering the latest developments according the various automation levels ( 0 to 5 ). The goals include making driving safer and more environmentally friendly, as well as protecting high quality production and jobs, which together will secure our prosperity. The automobile and our very systems of transportation are being reinvented. The opportunities for engineers are many and exciting.

But wait! Even if driver-assistance and automation systems actually work the way they are supposed to and we master the crucial issues of functional safety and security, we can still ask ourselves: "Is this good for people?" While the complex relationship between humans and machines is not new, and many efforts are being made to ensure high user-acceptance levels, including the deployment of ergonomists and psychologists, as well as test subjects to ensure reliable simulation studies, there is far more to be done. In fact, we need to be willing to reconsider everything. Instead of introducing ever newer products with ever more functions, would it not be better to take the time to consider what people actually need and want, and use that as a basis for deriving product requirements? That would not only be more sustainable, it would give us an opportunity to encounter and include, for instance, people who have aged and who therefore have to contend with physical and sensory impairment. We would better grasp the significance of demographic changes. "As our longevity increases, we're also more likely to experience impairment because our bodies, in bioevolutionary terms, weren't conceived for such extended lives," says Ulrich Schiefer, who teaches ophthalmology at Aalen University and works as an ophthalmologist at the University of Tübingen Medical Center.

On its research roadmap, the eNOVA Strategy Board for the Automobile Future defines its 2035 milestone as follows: "Achieving integrated, sustainable and user-friendly transportation via an intelligent, seamless, and automated interplay of vehicle, infrastructure and human." I am encouraged to see an emphasis on the human component here, and I will continue to promote "technology for people" instead of "people for technology.” 